\title{
Desinstitucionalização em debate: uma etnografia em eventos de saúde mental
}

\author{
Deinstitutionalization in debate: an ethnography in mental health \\ events
}

Milene Santiago Nascimento', Martinho Braga Batista e Silva'

DOI: 10.1590/0103-11042020E305

RESUMO Com o objetivo de identificar os usos do termo desinstitucionalização e os significados atribuídos a ele no campo da saúde mental, uma breve revisão bibliográfica foi acompanhada de uma etnografia em cinco eventos ao longo de dois anos. Confundido, na maioria das vezes, com desospitalização e ancorado nas contribuições da psiquiatria democrática italiana à reforma psiquiátrica brasileira, o conceito de desinstitucionalização aponta para mais de uma possibilidade de desmontar e/ou desconstruir saberes e práticas psiquiátricas. Além disso, trabalhadores, usuários, pesquisadores e outros participantes de congressos científicos e demais formas de encontro presencial apontam para a relevância de promover valor social nos processos de desinstitucionalização, indicando estratégias para aumentar o poder contratual em meio aos debates políticos.

PALAVRAS-CHAVE Desinstitucionalização. Pesquisa qualitativa. Saúde mental.

\begin{abstract}
Aiming to identify the uses of the term deinstitutionalization and the meanings attributed to it in the field of mental health, a brief bibliographic review was accompanied by an ethnography in five events over two years. Mostly confused with dehospitalization and anchored in the contributions of Italian democratic psychiatry to Brazilian psychiatric reform, the concept of deinstitutionalization points to more than one possibility of dismantling and / or deconstructing psychiatric knowledge and practices. In addition, workers, users, researchers and other participants in scientific congresses and other forms of face-to-face meetings point to the importance of promoting social value in deinstitutionalization processes, indicating strategies to increase contractual power among the political debates.
\end{abstract}

KEYWORDS Deinstitutionalization. Qualitative research. Mental health.

1 Universidade do Estado do Rio de Janeiro (Uerj), Instituto de Medicina Social (IMS) - Rio de Janeiro (RJ), Brasil. milenesantiago@hotmail. com 


\section{Introdução}

O campo da saúde mental reúne trabalhadores, gestores e usuários de serviços, bem como seus familiares e vizinhos, do mesmo modo como professores, pesquisadores, poetas e outros atores sociais que contribuem para a inclusão social de pessoas em situação de sofrimento psíquico. Esse campo emerge ao longo do processo da Reforma Psiquiátrica Brasileira, inspirado em experiências internacionais de transformação da assistência psiquiátrica nos Estados Unidos da América e na Europa - neste continente, particularmente, Itália, também Reino Unido e França' ${ }^{1}$. Esse processo ultrapassa a transformação da assistência psiquiátrica, uma das dimensões e não a única dele, designada técnico-assistencial, pois ele envolve outras três dimensões: jurídico-política (a Lei ${ }^{\circ}$ 10.216/2001 foi uma conquista nesse sentido), sociocultural (blocos de carnaval como Loucura Suburbana foram simbólicos nesta direção) e teórico-conceitual/epistemológica (colocar a doença mental entre parênteses ilustra essa operação) $)^{\mathbf{1} 2}$. A dimensão epistemológica do processo de Reforma Psiquiátrica Brasileira contribuiu tanto quanto as outras dimensões para a consolidação do campo da saúde mental, situando o saber psiquiátrico como uma forma de conhecimento científico articulado com modalidades variadas de controle social, como é o caso do tratamento moral no alienismo dos séculos XVIII e XIX ${ }^{3}$.

O processo de Reforma Psiquiátrica Brasileira foi desencadeado em meio à constituição do Movimento Nacional da Luta Antimanicomial e se desdobrou em políticas de saúde mental, álcool e outras drogas. Nessas políticas, a assistência psiquiátrica hospitalar perdeu espaço para a atenção psicossocial no território na passagem do século XX para o $\mathrm{XXI}^{4}$. Beneficiamo-nos da psiquiatria preventiva norte-americana, das comunidades terapêuticas e da antipsiquiatria inglesas, da psiquiatria institucional e da psiquiatria de setor francesas e, principalmente, da psiquiatria democrática italiana na fabricação do que chamamos serviços alternativos à cronificação asilar 5 . Terminamos por valorizar o protagonismo dos usuários desses serviços e dos militantes, artistas e demais pessoas com transtorno mental que ajudaram a lutar por uma sociedade sem manicômios.

Além de atenção psicossocial no território, outros conceitos emergiram no campo da saúde mental e, assim, relevaram a importância da dimensão epistemológica do processo de Reforma Psiquiátrica Brasileira, como é o caso de contratualidade ${ }^{6}$ e desinstitucionalização ${ }^{7}$.

A expressão desinstitucionalização frequentemente é utilizada por autores e atores do campo da saúde mental brasileiro como sinônimo de desospitalização, sem qualquer referência ao conceito e geralmente com o significado de saída do paciente de dentro de hospital. O uso do termo ganha força, sobretudo, com a Portaria ${ }^{0} 3.088$, de 2011, que institui a Rede de Atenção Psicossocial (Raps) e a situa como um de seus sete componentes, ou seja, "Estratégias de desinstitucionalização"8. O uso desse termo se tornou tão naturalizado pelos agentes que compõem o citado campo que a desinstitucionalização passou a ser chamada de 'desins' ou mesmo 'desinsti'.

Quais os usos e significados de desinstitucionalização no campo da saúde mental? Certamente, encontraremos polissemia nessa investigação, sendo que, para nós, desinstitucionalização diz respeito ao processo contínuo de desmontagem dos saberes e práticas que colaboram para manter a experiência da loucura como sinônimo de doença mental, a instituição a ser interrogada se referindo não só à física - o próprio manicômio -, mas também ao conjunto de aparatos médicos, jurídicos e morais que fazem com que suspeitemos que toda pessoa com transtorno mental é potencialmente incapaz, irresponsável, incurável e perigosa - simbólica portanto.

Dessa forma, nosso objetivo é identificar os diferentes usos e significados para a desinstitucionalização no campo da saúde mental, particularmente os que emergem em espaços nos quais seus agentes promovem debates sobre esse tema, como os eventos científicos. 


\section{Metodologia}

Com o objetivo de estudar os sentidos de território no campo da saúde mental, documentos científicos - artigos exclusivamente - e estatais - portarias e cartilhas, entre outros - publicados ao longo das últimas décadas foram reunidos e sistematizados ${ }^{9}$. A análise dos documentos permitiu aos autores distinguirem quatro acepções de território: 1) como área de cobertura e ação de serviços extra-hospitalares, ou seja, conjunto de cuidados em saúde de determinado território geográfico; 2) território como conjunto de recursos terapêuticos que potencializam o cuidado de pessoas com transtornos mentais graves; 3 ) território como existência, no qual estão envolvidos aspectos subjetivos, sociológicos, como lugar de construções simbólicas e pertencimento; 4) território como interface entre o político e o cultural, cunhado por Milton Santos. As duas primeiras acepções constituem o polo de dominância funcional; e os dois últimos, o polo de dominância simbólica. Como esses autores, procuraremos tipologizar os sentidos do termo desinstitucionalização com base em uma análise documental - no nosso caso, livros sobre o tema.

Segundo os citados autores, "o processo italiano de desinstitucionalização e inclusão territorial pressupõe disputas e embates nada alinhados à noção funcional de território"9(10), de maneira que apontam para a possibilidade de nossa investigação sobre os usos e sentidos de desinstitucionalização no campo da saúde mental fortalecer a dimensão simbólica do termo. Esses mesmos autores também nos advertem:

Estamos numa encruzilhada entre a verdadeira inserção no território e uma transinstitucionalização. Se a primeira representa conflitos, o difícil convívio com a diferença e avanços por vezes lentos e sempre parciais, a segunda representa somente a saída do hospital psiquiátrico em direção à tutela na comunidade, conduzida por profissionais de instituições como os Caps e os SRT ${ }^{9(10)}$.
Além disso, compartilhamos com os referidos autores a perspectiva segundo a qual o campo da saúde mental é semelhante ao campo da saúde coletiva, ou seja, seus agentes mobilizam capitais burocráticos e científicos para se legitimarem nesse espaço social. Desse modo, muitos dos 'mentaleiros' são assim considerados por circular entre órgãos do Poder Executivo - como secretarias municipais, seja como trabalhador ou gestor - e instituições de ensino - seja como pesquisador ou professor -, e não apenas um deles isoladamente. Acrescentaremos à análise documental a observação participante de eventos promovidos por agentes do campo da saúde mental, justamente na expectativa de compreender os usos e os sentidos de desinstitucionalização com os próprios agentes que são autorizados a falar em nome da 'saúde mental'.

Nos eventos, utilizamo-nos da proposta da 'etnografia de interface'10. Trata-se de uma forma de realizar a observação participante em eventos públicos de um campo familiar, no qual nos encontramos como agentes, já que fomos trabalhadores da saúde mental. Isto é, falas, termos, significados que são próprios do campo da saúde mental são compartilhados externamente, uma vez que, nesses espaços, é permitida a presença de agentes que não necessariamente frequentam esse campo.

A etnografia de interface é mais uma alternativa ao etnógrafo, que precisa ser criativo em suas ferramentas antropológicas, já que

'halfway' or 'interface' spaces in which some sort of revelations about insider's ways of thinking and talking and (re)presenting themselves might be heard and seem ${ }^{10(219)}$.

Para essa autora, os eventos se situam em um 'entre', em que as pessoas se apresentam, relatam suas experiências, permanecendo essas falas em domínio público.

Ao etnografar um evento da Associação Brasileira de Psiquiatria, especificamente a área de estandes, outro autor evidenciou o marketing relacionado aos psico/neurofárma$\cos ^{11}$. Ele descreveu como se preparou para a 
atividade (estratégias utilizadas para a construção do pré-campo, como estudo teórico e encontro prévio com alguns agentes do campo), a área física do evento, dos estandes, nos apresentando as características deste e de seus participantes (com recorte de idade, gênero e formação), bem como o critério de seleção dos espaços etnografados.

Entendemos que os eventos do campo da saúde mental são ricos, não somente no que tange aos debates, mas pela multiplicidade de agentes que participam. Cada um deles possui trajetória diferente, mobilizando capital distinto. Assim, congressos e demais eventos científicos e burocráticos se constituem um espaço fecundo para alcançarmos os usos e sentidos que o termo desinstitucionalização adquire.

O pertencimento ao campo da saúde mental contribui para compreensão do discurso científico sobre a desinstitucionalização e do arsenal linguístico encontrado nos eventos. Ambos os autores já foram trabalhadores da saúde mental e, atualmente, são pesquisadores. Esse pertencimento ao campo construiu, em cada pesquisador, um arsenal prévio de sentidos para o termo ‘desinstitucionalização'. A tarefa de identificar e caracterizar os sentidos acionados pelos agentes do campo evoca esse conjunto subjetivo e particular de valores, de conceitos já formulados e absorvidos, de significados estabelecidos. Assim, reconhecer essas pré-construções foi a primeira empreitada etnográfica.

A observação participante dos cinco eventos científicos e burocráticos do campo da saúde mental aconteceu entre os anos de 2018 e 2019; e o projeto de pesquisa foi submetido ao Comitê de Ética em Pesquisa, do Instituto de Medicina Social da Universidade do Estado do Rio de Janeiro, sendo autorizada pelo parecer número 3.386.261.

\section{Resultados e discussão}

A revisão bibliográfica e a visita aos eventos nos certificaram de características do campo da saúde mental: sua pluralidade de atores, a polissemia dos termos que lhe são próprios e sua disposição política. A diversidade de agentes, os debates e as práticas fazem da saúde mental um campo importante de disputas, de tomada de posições e construções coletivas, que envolve ações que objetivam intervenções sociais, cuidado aos usuários e construções teóricas.

Os resultados da pesquisa serão, a seguir, sistematizados em dois subitens: no primeiro, apresentaremos os significados do conceito desinstitucionalização apreendidos de uma breve revisão bibliográfica; no segundo, os usos do termo desinstitucionalização e os significados atribuídos a ele em debates ao longo de eventos burocráticos e científicos do campo da saúde mental serão identificados. A discussão dos resultados será conduzida nos próprios subitens.

\section{Desinstitucionalizações: desmontagens, desconstruções e níveis}

Realizamos uma revisão bibliográfica do conceito de desinstitucionalização em três referências que consideramos fundamentais para sua compreensão. A primeira delas constitui a definição clássica de desinstitucionalização, cunhada por Rotelli, Leonardis e Mauri em 1990, resultado da experiência dos autores na reforma psiquiátrica italiana ${ }^{12}$. A segunda referência é um marco do conceito de desinstitucionalização no Brasil, elaborado por Amarante em 1996, que a define a partir de três sentidos: desospitalização, desassistência e desconstrução ${ }^{\mathbf{1 3}}$. Por último, o referencial construído por Venturini mais recentemente, acentuando a polissemia para o termo e propondo os níveis de desinstitucionalização ${ }^{14}$. Um desses níveis, a promoção de valor social, ganhará destaque no próximo subitem, entre outras razões, por entendermos que ele remete a uma conquista do movimento pela Reforma Psiquiátrica Brasileira.

Para os primeiros autores citados, a desinstitucionalização representa a desconstrução 
de um modelo hegemônico de pensamento, a psiquiatria clássica. $O$ conceito remete não somente ao espaço físico do manicômio, mas, sobretudo, à instituição simbólica:

[...] trabalham com a hipótese de que o mal obscuro da Psiquiatria está em haver separado um objeto fictício, 'a doença', da 'existência global complexa e concreta' dos pacientes e do corpo social. Sobre esta separação artificial se construiu um conjunto de aparatos científicos, legislativos, administrativos (precisamente a 'instituição'), todos referidos à 'doença'. É este conjunto que é preciso desmontar (desinstitucionalizar) para retomar o contato com aquela existência dos pacientes, enquanto 'existência' doente ${ }^{\text {12(27-28). }}$

Para esses reformadores italianos, a desinstitucionalização é um processo social contínuo de transformação, no qual os técnicos exercem mais do que uma prática terapêutica, já que "eles fazem também, indiretamente, política"12(32). A desinstitucionalização, nessa visão, requer uma relação direta com o território, volta-se mais para as pessoas do que para as instituições:

Trata-se de negar o hospital psiquiátrico salvaguardando o direito de assistência, de negar a 'política de setor' salvaguardando a unicidade de responsabilidade sobre um território determinado, de negar a comunidade terapêutica em favor de uma comunidade difusa, de negar o monopólio dos técnicos utilizando ao máximo suas potencialidades para ativar os recursos da pessoa. Esta linha de atuação é o que se entende em Trieste concretamente por desinstitucionalização ${ }^{\mathbf{1 2 ( 4 2 )} \text {. }}$

Para um dos principais teóricos e militantes da Reforma Psiquiátrica Brasileira, a concepção de desinstitucionalização no Brasil contou em muito com a contribuição desses reformadores italianos ${ }^{13}$. Segundo seu ponto de vista, a desinstitucionalização se afirma quando a reforma psiquiátrica deixa de ser apenas uma bandeira dos trabalhadores do campo da saúde mental e se transforma em um movimento social e democrático. Esse autor indica que existe uma pluralidade de atores e fazeres em saúde mental, todos sob o título de desinstitucionalização. Ele considera que a forma de lidar e pensar a desinstitucionalização impõe uma distinção entre os variados projetos da reforma psiquiátrica. Nesse sentido, propõe três sentidos possíveis para a desinstitucionalização no Brasil: desospitalização, desassistência e desconstrução.

A desinstitucionalização como desospitalização refere-se às medidas de prevenção de internações inadequadas em hospitais psiquiátricos; alta para o tratamento na comunidade; e implantação de serviços de base comunitária para o cuidado dos egressos das internações. Essa prática de desinstitucionalização está voltada, sobretudo, aos objetivos administrativo-financeiros do Estado. Para o referido autor, trata-se do mesmo projeto tradicional das práticas psiquiátricas, apenas humanizadas, garantidas por uma mudança operacional.

A desinstitucionalização como desassistência é a marca da crítica realizada aos princípios da desinstitucionalização, levantada por interesses ou grupos que dependem financeiramente do êxito das internações hospitalares e corporações farmacêuticas. Trata-se de uma "tendência contradesinstitucionalizante"13(19) com base na suspeita de que os pacientes, ao saírem dos hospitais psiquiátricos, ficariam abandonados, já que não haveria um suporte para o cuidado.

A desinstitucionalização como desconstrução indica o momento em que a reforma psiquiátrica brasileira se transforma em um movimento social, e não apenas a especificidade de um grupo, como o Movimento dos Trabalhadores da Saúde Mental. Como desconstrução, a desinstitucionalização coloca em questão o conceito de doença mental, pois ele impõe limites aos direitos dos cidadãos. Assim, trata-se de um processo de ruptura prático-teórica com o saber constituinte e o campo específico da psiquiatria. 
Finalmente, outro reformador italiano contribui para entendermos a polissemia do termo, a partir da distinção entre a verdadeira e a falsa desinstitucionalização e suas reflexões sobre os níveis de desinstitucionalização ${ }^{\mathbf{1 4}}$. Para o autor, a falsa desinstitucionalização indica um simples processo de desospitalização ou transinstitucionalização, enquanto a verdadeira desinstitucionalização opera uma transformação do paradigma da psiquiatria. São os equívocos em processos de desinstitucionalização - que sofrem influência de políticas neoliberais - e a constatação da negação e desvirtuação dos princípios fundamentais da desinstitucionalização que contribuíram para essa distinção. Ademais, o autor propõe quatro níveis em progressão da desinstitucionalização: desospitalização, habilitação psicossocial, inclusão social e promoção de valor social. Esses níveis são divididos em dois grupos descontínuos: desospitalização e desinstitucionalização.

Para o autor, a desospitalização é o processo que não intervém no tecido social. Trata-se de um processo de humanização do hospital psiquiátrico e redução do número de leitos e internações. A habilitação psicossocial, primeiro nível da desinstitucionalização, envolve a aceleração de altas, com algumas intervenções significativas em relação à regressão institucional, mas sem ação sobre os mecanismos sociais que constrangem a experiência da loucura ou do sofrimento psíquico. O segundo nível é a inclusão social, que incide nas instituições psiquiátricas mudando o circuito psiquiátrico. Desconstrói o manicômio, erigindo ações solidárias. Envolve intervenções no nível social, jurídico, político e incide sobre tratamentos e cuidados. A promoção de valor social é o terceiro nível da desinstitucionalização e atua sobre uma comunidade, desconstruindo o estigma e as representações sociais e culturais tradicionais da doença.

Entre todos os níveis da desinstitucionalização, a promoção de valor social representa uma mudança na comunidade. Trata-se de um processo de valorização social, que envolve práticas de emancipação (acesso aos estudos, moradia adequada, condições de trabalho e renda, liberdade sexual, livre expressão, promoção individual e qualidade de vida); disponibilidade efetiva de recursos e direito de acessá-los, que engloba, além dos anteriormente descritos, as relações sociais viáveis; acesso a diversos valores - autonomia, instrução, formação profissional, capacidade social, exercício de poder e capacidade de expressão de valores e concepções pessoais; desenvolvimento das trocas sociais e da cooperação. Todos esses aspectos se referem ao conceito de contratualidade social ${ }^{6}$. Isso significa que a valorização social tem como um de seus efeitos a viabilização do sujeito na sociedade, empreendendo trocas, exercendo direitos e se envolvendo no planejamento de políticas sociais e nas políticas de saúde mental. Assim, a desinstitucionalização como promoção de valor social interfere mais no tecido social do que no sujeito particular.

\section{Debates sobre desinstitucionalização em eventos científicos e burocráticos}

Os eventos do campo da saúde mental são caracterizados por uma riqueza de debates e multiplicidade de atores. São trabalhadores, estudantes, usuários, militantes, familiares e pesquisadores, que fazem dos eventos um espaço singular para conhecimento da realidade e do contexto da saúde mental e de suas práticas.

Outra característica importante dos eventos do campo da saúde mental é a construção de estratégias que visam à prática de cuidado e uma intervenção no tecido social, na tentativa de uma transformação social do imaginário acerca da loucura e do sofrimento psíquico.

Os eventos etnografados se configuravam em diferentes modalidades: simpósio, congresso, fórum e grupo de estudos. A maioria dos eventos foi organizada por entidades da sociedade civil e universidades, estas sendo também a sede de grande parte deles, dado o grande número de participantes. Outrossim, possuem espaços coletivos, como feiras de economia 
solidária, exposições e área de alimentação, em que seus participantes circulam e continuam algumas discussões disparadas nas apresentações de trabalhos e nas mesas redondas.

Apenas um dos cinco eventos etnografados não é científico, dizendo respeito ao campo burocrático da saúde mental. Esse evento regional mensal discute, com mais frequência, questões relativas às dificuldades na relação entre os serviços da Rede de Saúde, falta de suporte das estruturas de gestão e da área técnica de saúde mental para desenvolvimento de ações que visem à desinternação. A análise da conjuntura política atual e os impactos nos processos de desospitalização e consolidação da Raps sempre comparecem nos encontros. O tema ‘desinstitucionalização’ é pouco abordado. O termo é mencionado poucas vezes, de maneira prescritiva ou conceitual.

O Congresso Nacional Bienal do Campo Científico discute, com maior frequência, práticas de cuidado em saúde mental, protagonismo do usuário e a temática álcool e outras drogas. O evento estava esvaziado, com pouco movimento de militância e poucas manifestações acerca das mudanças na política nacional de saúde mental. Neste momento da atualidade, em que observamos um retorno a práticas manicomiais, a desinstitucionalização não aparece como eixo temático, embora o termo tenha aparecido em 21 trabalhos, sendo título de uma mesa redonda.

Outro Evento Nacional Bienal do Campo Científico abordou com maior frequência questões sobre autonomia, protagonismo e direitos dos usuários, desinstitucionalização, avaliação da rede e serviços quanto à garantia dos direitos humanos, Hospitais de Custódia e Tratamento Psiquiátrico (HCTP); e a temática álcool e outras drogas e sua relação com a desinstitucionalização. Estes últimos temas não são frequentes nos eventos, o que nos levou a uma dificuldade de identificar e caracterizar os sentidos de desinstitucionalização nesses debates. As conversas e as reflexões sobre desinstitucionalização foram frequentes: temas de mesas redondas e de trabalhos (relatos de pesquisa e experiência). $\mathrm{O}$ evento destacou-se pela quantidade de usuários e militantes ocupando mesas de debates, fazendo com que ele se caracterizasse por uma forte movimentação política. Além disso, percebeu-se que o termo desinstitucionalização é usado de forma diferente pelos trabalhadores e pelos usuários.

O Congresso Nacional Trienal no Campo Científico foi politizado e amplo. Discutiu com grande frequência o protagonismo de usuários e familiares no cuidado e no processo de desinstitucionalização; a relação entre saúde mental e atenção básica; a formação e a educação popular em saúde; e a desinstitucionalização e sua relação com ampliação da Raps. O evento destacou-se por debater sobre práticas de neoinstitucionalização; por trazer uma concepção de polissemia relacionada com as práticas de desinstitucionalização, diferentemente da polissemia atribuída ao conceito ${ }^{\mathbf{1 4}}$.

O Evento Regional Anual do Campo Científico trouxe muitas reflexões sobre os retrocessos na política de saúde mental e formas de enfretamento; destacou-se por abordar a transinstitucionalização; tratou sobre a desinstitucionalização, a história da reforma psiquiátrica e contribuições da sua memória para os momentos atuais.

Durante a observação participante, encontramos diferentes sentidos relativos à desinstitucionalização, como: estratégia, cuidado, rede territorial, humanização, desospitalização, mudança de postura do profissional, desconstrução da lógica manicomial, entre outros. Para análise dos achados, esses sentidos foram agrupados de acordo com os níveis de desinstitucionalização, caracterizando o seguinte cenário: 1) desospitalização (desospitalização; mudança da postura do profissional); 2) habilitação psicossocial (alta assistida / acompanhamento terapêutico);3) inclusão social (rede de cuidado territorial / Raps / estratégias de desinstitucionalização / cuidado: integralidade, promoção de saúde; reabilitação psicossocial / Serviço Residencial Terapêutico/ inserção no trabalho; inserção social / cidadania / direitos / autonomia); 4) promoção de valor social (desconstrução da lógica manicomial). 
Quadro 1. Sentidos de desinstitucionalização

\begin{tabular}{|c|c|c|c|c|}
\hline Evento & Ano & Participantes & $\begin{array}{l}\text { Desinstitucionalização } \\
\text { no Tema / Eixo temático }\end{array}$ & $\begin{array}{l}\text { Sentido mais frequente } \\
\text { de Desinstitucionalização }\end{array}$ \\
\hline $\begin{array}{l}\text { Evento Regional } \\
\text { Mensal do Campo } \\
\text { Burocrático }\end{array}$ & Contínuo & $\begin{array}{l}\text { Trabalhadores da instituição promotora, eventual- } \\
\text { mente usuários, seus familiares e gestão; trabalha- } \\
\text { dores da Raps; graduandos, mais frequentemente } \\
\text { dos cursos de Psicologia e Direito; pesquisadores do } \\
\text { campo da psicologia e do direito }\end{array}$ & Presente & Desospitalização \\
\hline $\begin{array}{l}\text { Congresso Nacional } \\
\text { Bienal do Campo } \\
\text { Científico }\end{array}$ & 2018 & $\begin{array}{l}\text { Trabalhadores, usuários, familiares da Raps; mili- } \\
\text { tantes e pesquisadores do campo da saúde mental; } \\
\text { graduandos, mais frequentemente dos cursos de } \\
\text { Psicologia, Enfermagem e Terapia Ocupacional (TO) }\end{array}$ & Ausente & Desospitalização \\
\hline $\begin{array}{l}\text { Evento Nacional } \\
\text { Bienal do Campo } \\
\text { Científico }\end{array}$ & 2019 & $\begin{array}{l}\text { Muitos representantes de grupos sociais - indíge- } \\
\text { nas, negros, LGBTIA+, saúde mental; Trabalhadores } \\
\text { e usuários Raps; graduando, mais frequentemente } \\
\text { dos cursos de Enfermagem, Psicologia e TO; pes- } \\
\text { quisadores do campo da saúde mental. }\end{array}$ & Presente & Desospitalização \\
\hline $\begin{array}{l}\text { Congresso Nacional } \\
\text { Trienal no Campo } \\
\text { Científico }\end{array}$ & 2019 & $\begin{array}{l}\text { Trabalhadores e pesquisadores do campo da saúde } \\
\text { coletiva; graduandos cursos do campo da saúde; re- } \\
\text { presentantes de grupos sociais (indígenas, negros, } \\
\text { LGBTIA+, saúde mental, HIV+, entre outros) }\end{array}$ & Ausente & Promoção de valor social \\
\hline $\begin{array}{l}\text { Evento Regional } \\
\text { Anual do Campo } \\
\text { Científico }\end{array}$ & 2019 & $\begin{array}{l}\text { Alunos do mestrado profissional em atenção psi- } \\
\text { cossocial da instituição promotora e mestres re- } \\
\text { cém-formados; trabalhadores da Raps e da Rede de } \\
\text { Saúde; pesquisadores do campo da saúde mental }\end{array}$ & Presente & Promoção de valor social \\
\hline
\end{tabular}

O quadro acima demonstra que 'promoção de valor social' é um dos sentidos de desinstitucionalização presente nas falas dos participantes dos cinco eventos etnografados, do mesmo modo como 'desospitalização'. Mais do que isso, nota-se que 'promoção de valor social' é o sentido mais frequente do termo desinstitucionalização em dois dos cinco eventos. Com valor demonstrativo e comparativo, o quadro indica a 'promoção de valor social' como um sentido relevante para compreendermos desinstitucionalização. Ressalta-se que 'promoção de valor social' é mais utilizado em falas prescritivas; e quando o termo desinstitucionalização é acionado, é em uma vertente teórica-conceitual.

A 'promoção de valor social' é o sentido que mais se aproxima da verdadeira desinstitucionalização ${ }^{\mathbf{1 4}}$, da desconstrução ${ }^{\mathbf{1 3}} \mathrm{e}$ da contratualidade $^{6}$, diferentemente da desospitalização. Por essa razão, optamos por apresentar o significado de desinstitucionalização como promoção de valor social conforme ele aparece nos debates em eventos científicos e burocráticos, embora tenha sido utilizado com menos frequência que desospitalização.

No Evento Regional Mensal do Campo Burocrático, participam usuários do serviço, trabalhadores da Raps, do campo jurídico e do campo científico. Os debates são disparados a partir de falas apresentadas por convidados, que são engendradas por temas escolhidos previamente. Os temas giram em torno da relação entre saúde mental, saúde e campo jurídico. É interessante notar que a direção do debate visa à desinstitucionalização. Entretanto, como assinalamos, nem sempre ela é pauta ou é, sequer, mencionada.

Em um dos encontros, discutiu-se sobre o aparato psicossocial que coloca a experiência da loucura como sinônimo de periculosidade. Os participantes debateram sobre estratégias 
de intervenção em nível social para a desconstrução desse estigma, ou seja, o 'louco perigoso'. Pudemos identificar o sentido de promoção de valor social atrelado ao uso de desinstitucionalização:

a desinstitucionalização precisa mirar a estrutura social, que define que o louco é perigoso. Não é o diagnóstico quem diz que o doente é perigoso, mas sim esse discurso.

Em outro encontro, durante debate sobre o encarceramento feminino em HCTP, novamente identificamos a desinstitucionalização sendo utilizada no sentido de promoção de valor social:

precisamos desinstitucionalizar, criar condições dessa mulher sair do HCTP e existir no território. Não é suficiente tirar ela do hospital, mas criar condições de vida, ter acesso à cidade: educação, lazer, casa, trabalho.

No Congresso Nacional Bienal do Campo Científico, ocorrido em 2018, o sentido de promoção social também foi algumas vezes acionado. $\mathrm{O}$ evento possui atividades acontecendo simultaneamente, o que dificulta estar presente em muitas atividades. Contou com milhares de participantes, entre militantes, usuários, familiares, profissionais e alunos de diversos cursos de graduação.

Havia, na área dos estandes, uma exposição de fotos, em comemoração aos 15 anos do Programa De Volta Para Casa. Nos banners da exposição, a desinstitucionalização foi colocada ao lado de contratualidade social, indicando, novamente, o sentido de promoção social:

A desinstitucionalização e a reabilitação psicossocial são estratégias que vão além da desospitalização e abrigamento, passam pela reconstrução de histórias de vida, de rede social, emprego, lazer, moradia entre outras necessidades que se superpõem à clínica.

Em uma das mesas-redondas, cujo título continha a palavra desinstitucionalização, ela também compareceu com o sentido promoção de valor social: "a desinstitucionalização é uma prática territorial, cuja intervenção se dá na cultura, no imaginário em torno da loucura". Na mesma mesa, outros participantes também destacaram o sentido de promoção de valor social:

a desinstitucionalização é mudança de pensamento. É preciso que a sociedade saiba lidar com o diferente.

a desins envolve ação de transformação no território, para oferecer um lugar social para o sujeito.

O Evento Nacional Bienal do Campo Científico contou com público semelhante ao anterior, embora com mais representantes de grupos sociais e militantes da saúde mental. O sentido promoção de valor social também compareceu, sobretudo quando o termo desinstitucionalização era acionado com um caráter mais teórico e ideológico.

Em um dos relatos de experiência, sobre a experiência de um profissional que compôs uma "comissão de desinstitucionalização de um município no interior da Bahia", a desinstitucionalização ganhou o sentido de promoção de valor social: "a desinstitucionalização dá lugar à diferença, à loucura... é criação de novas possibilidades de vida", destacou a participante; e em seguida descreveu as ações de desinstitucionalização empreendidas pela comissão. Entre as ações, nos chamou a atenção aquelas que Venturini sinaliza como estratégias de valorização social: "busca de vínculos no território, construção de formas de moradia, ocupação de espaços sociais".

O Congresso Nacional Trienal no Campo Científico foi mais amplo que os demais, pelo fato de não se tratar de um evento específico do campo da saúde mental, mas da saúde coletiva. A saúde mental foi um tema de grupos de trabalho, nos quais também pudemos ver a desinstitucionalização sendo utilizada com o sentido de 'promoção de valor social': 
A reforma psiquiátrica prioriza ações de desinstitucionalização, com vistas a superar a lógica manicomial que segrega a pessoa com sofrimento mental, oferecendo um novo lugar social para o sujeito.

Para um dos teóricos da desinstitucionalização, "a cidade do século XXI é desumana"14(131). Ela cancela o lugar do encontro, do conflito e da democracia. Cada vez mais, observamos o estrangeiro mais estranho: à margem, em seus lugares destinados. Os interesses frágeis são negligenciados; são os interesses das crianças, dos jovens que têm seus espaços predeterminados por adultos, dos idosos, dos doentes mentais, dos imigrantes. Para estes, a sociedade fecha seus olhos. Os lugares definidos pela sociedade pertencem ou são permeados por aqueles com 'nome e sobrenome', ou com destino determinado: lugares de consumo, de lazer, de turismo... o acesso a esses espaços é regulado.

Assim, quando os agentes do campo da saúde mental tomam a desinstitucionalização por 'promoção de valor social' ampliam o conceito, não o reduzindo somente ao eixo cuidado. Esse sentido sugere que as ações de desinstitucionalização se voltem justamente para o espaço social cancelado, ou àquele prescrito, que não atende aos interesses de pessoas que estão à margem:

Vivemos hoje numa aldeia eletrônica global e os pontos de referência são instáveis e não identificáveis. Além disso, dentro de uma mesma área convivem culturas diversas. A nova cidade deverá definir-se por um caráter laico de tipo novo, sem a memória embaraçosa do pertencimento... o grau de entropia, física e social impõe a todos uma consideração plena de necessidades e dos direitos de todos os cidadãos ${ }^{14(137)}$.

Para que essa operação seja possível, sob a perspectiva da promoção de valor social, o papel do trabalhador do campo da saúde mental é fazer a engrenagem social funcionar:

acionando uma rede de microiniciativas, alimentando trocas, provocando a reprodução social, construindo um tecido social composto

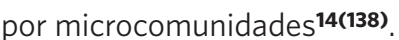

Paradoxalmente, são os invisíveis que movimentam essas microcomunidades, por constituírem em seu entorno uma rede de apoio. Nesse sentido, a cidade deve ser reabilitada para que ela mesma possa reabilitar.

A reabilitação psicossocial é uma "exigência ética”15(19), própria de um campo que tem como prioridade uma abordagem ética da saúde mental. Como estratégia global, implica uma ruptura com uma política de serviços tradicionais de saúde mental, envolve diversos atores, como profissionais, pacientes, familiares e comunidade; e se coloca no nível de construção ou potencialização de habilidades. Na reabilitação psicossocial, está envolvida a concepção de habilidade para contratualidade, isto é, elementos que possibilitam a produção de valor social. São esses elementos que permitem o sujeito circular em um espaço de troca. Assim, de acordo com o autor, os cenários nos quais se efetiva a reabilitação psicossocial são: 1) o habitat, ou seja, a apropriação de um espaço mais íntimo, a casa, a habitação; 2) a rede social, caracterizada pela participação nas trocas de identidades sociais, a circulação em espaços sociais e o lazer; 3) o trabalho como aquele que articula os desejos, os interesses e a produção de objetos com valor social.

A desinstitucionalização como promoção de valor social, portanto, é movimentar o tecido social, tendo como palavras-chave: contratualidade social, direitos, reciprocidade, subjetividade. O foco deixa de ser o sujeito louco, em sua condição existencial de perigoso, crônico, incapaz e inimputável:

O homem precisa conviver com o diverso dele mesmo, para descobrir a si próprio: porque a cidade, em uma escala humana, tem de ser a cidade de todos. A cidade não agressiva é, portanto, a cidade que cresce solidariamente, que pratica o respeito e que não tem medo de suas contradições ${ }^{\mathbf{1 4}(139)}$. 


\section{Considerações finais}

A pesquisa registrou uma polissemia em torno do termo desinstitucionalização. Foram vários sentidos identificados, tanto na literatura científica quando nos eventos visitados. O que mais nos chamou atenção foi o sentido 'promoção de valor social', por meio do qual podemos pensar sobre a ideia de contratualidade social.

É admissível extrairmos duas reflexões deste estudo. A primeira delas refere-se à caracterização do conceito de desinstitucionalização nos polos de dominância funcional e de dominância simbólica ${ }^{9}$. A segunda refere-se às consequências de significar desinstitucionalização a partir de promoção de valor social, que aponta para a intersetorialidade.

Considerando a concepção dos supramencionados autores, no polo de dominância funcional, estão os sentidos de desinstitucionalização referentes ao pragmatismo do cuidado e cotidiano dos serviços, sem um alcance simbólico, ou seja, desospitalização, habilitação psicossocial e inclusão social. No polo de dominância simbólica, está o sentido que relaciona a desinstitucionalização com a vertente da existência, subjetiva, social, político e cultural, ou seja, a promoção de valor social.

Significar a desinstitucionalização a partir da promoção de valor social nos leva a pensar sobre a intersetorialidade. A promoção de valor social envolve aspectos que vão além do sujeito em sofrimento, isto é, a reconstrução de todo um aparato social a partir das ideias de solidariedade, liberdade, trocas, cooperação, exercício de poder, bem como aspectos como moradia, trabalho, renda e lazer. Assim, ela se aproxima do que um dos reformadores italianos concebe como reabilitação psicossocial15 e implica uma ampliação da rede, de serviços e de atores.
Os eventos etnografados poderiam apontar para mais usos e significados da desinstitucionalização, além dos apresentados anteriormente. O contexto político-institucional no qual essas atividades coletivas e públicas aconteceram determinou, em grande parte, esse leque potencial de sentidos contidos nos enunciados dos participantes. Assim, o momento de retrocesso vivido no campo da saúde mental, após o golpe de 2016, certamente influenciou a viabilidade de um debate sobre a desinstitucionalização nesses espaços. Isto porque eles reúnem pessoas que circulam ao mesmo tempo pela academia, pelo serviço e pela militância, que se afetam pelas medidas arbitrárias do governo federal, como é o caso da Nota Técnica ${ }^{\circ}$ 11/2019, uma tentativa de incluir os hospitais psiquiátrico na Raps ${ }^{16}$.

Com estas considerações, é viável afirmamos que a desinstitucionalização enquanto promoção de valor social, com vistas à construção de contratualidade social, requer um aumento do grau de intersetorialidade. Isso significa uma ampliação ou a inclusão de outros dispositivos da rede que extrapolam o segmento da saúde para a que a desinstitucionalização se efetive.

\section{Colaboradores}

Nascimento MS (0000-0002-5132-1723)* contribuiu para participação dos eventos estudados, elaboração do conteúdo, e análise e interpretação dos dados. Silva MBB (00000003-3577-958X)* contribuiu para concepção do artigo, análise e interpretação dos dados, e revisão crítica do conteúdo. 


\section{Referências}

1. Amarante P, organizador. Loucos pela vida: a trajetória da reforma psiquiátrica no Brasil. Rio de Janeiro: Fiocruz; 1995.

2. Yasui S. Rupturas e encontros: desafios da reforma psiquiátrica brasileira. Rio de Janeiro: Fiocruz; 2010.

3. Pinel P. Tratado médico-filosófico sobre a alienação mental ou a mania. Porto Alegre: UFRGS; 2007.

4. Brasil. Ministério da Saúde. Saúde Mental no SUS: Acesso ao Tratamento e Mudança do Modelo de Atenção. Relatório de Gestão 2003-2007. Coordenação Geral de Saúde Mental [internet]. Brasília, DF: Ministério da Saúde; 2007 [acesso em 28 fev 2020]. Disponível em: http://portal.saude.gov.br/portal/arquivos/pdf/relatorio_gestao_saude_mental_2006.pdf.

5. Kinoshita R. Em busca da cidadania. In: Campos F, Henriques C, organizadores. Contra a maré à beira-mar - A experiência do SUS em Santos. São Paulo: Página Aberta; 1996. p. 39-49.

6. Kinoshita R. Contratualidade e reabilitação Psicossocial. In: Pitta A. organizadora Reabilitação psicossocial no Brasil. São Paulo: Hucitec; 2001. p. 55-59.

7. Rotelli F, Leonardis O, Mauri D. Desinstitucionalização, uma outra via. In: Nicácio F, organizador. Desinstitucionalização. São Paulo: Hucitec; 2001. p. 17-59.

8. Brasil. Ministério da Saúde. Portaria $n^{\circ} 3.088$, de 23 de dezembro de 2011. Institui a Rede de Atenção Psicossocial para pessoas com sofrimento ou transtorno mental e com necessidades decorrentes do uso de crack, álcool e outras drogas, no âmbito do Sistema Único de Saúde (SUS). Diário Oficial da União. 2011 Dez 23. [acesso em 2019 ago 4]. Disponível em: http://bvsms.saude.gov.br/bvs/saudelegis/gm/2011/ prt3088_23_12_2011_rep.html.

9. Furtado J, Oda W, Borysow I, et al. A concepção de território na Saúde Mental. Cad. Saúde Públi- ca. 2016 [acesso em 2020 fev 28]; 32(9). Disponível em: http://www.scielo.br/scielo.php?script=sci arttext\&pid=S0102-11X2016000902001\&lng=en\&nr $\mathrm{m}=$ iso.

10. Ortner S. Access: reflections on studying up in Hollywood. 2010. [acesso em 2019 nov 9]. Disponível em: https://journals.sagepub.com/doi/ abs/10.1177/1466138110362006.

11. Azize R. Notas de um "não-prescritor": uma etnografia entre os estandes da indústria farmacêutica no Congresso Brasileiro de Psiquiatria. In: Maluf S, Torniquist C, organizadores. Gênero, saúde e aflição: abordagens antropológicas. Santa Catarina: Letras Contemporâneas; 2010. p. 367-401.

12. Rotelli F, Leonardis O, Mauri D. Desinstitucionalização, uma outra via. In: Nicácio F, organizador. Desinstitucionalização. São Paulo: Hucitec; 2001, p. 17-59.

13. Amarante P. O homem e a serpente. Rio de Janeiro: Fiocruz; 2010.

14. Venturini E. A linha curva: o espaço e o tempo da desinstitucionalização. Rio de Janeiro: Fiocruz; 2016.

15. Saraceno B. Reabilitação psicossocial: uma estratégia para a passagem do milênio. In: Pitta A, organizadora. Reabilitação psicossocial no Brasil. São Paulo: Hucitec; 2016. p. 19-26.

16. Guljor AP, Vasconcelos E, Couto MCV, et al. Nota de Avaliação Crítica da Nota Técnica 11/2019. [acesso em 2020 jul 28]. Disponível em: http://www.crprj. org.br/site/wp-content/uploads/2019/02/Note-tecnica-Saude-Mental.pdf.

Recebido em 29/02/2020

Aprovado em 04/08/2020

Conflito de interesses: inexistente

Suporte financeiro: Coordenação de Aperfeiçoamento de Pessoal

de Nível Superior (Capes) 